Article

\title{
Social Television Viewing with Second Screen Platforms: Antecedents and Consequences
}

\author{
Miao Guo \\ Department of Telecommunications, Ball State University, Muncie, IN 47306, USA; E-Mail: mmguo@bsu.edu
}

Submitted: 17 September 2018 | Accepted: 3 November 2018 | Published: 19 February 2019

\begin{abstract}
This study investigates the causal relationship between antecedents and consequences of social television viewing combining the television screen and concurrent use of a mobile, "second screen" media platform. The results indicate that social television viewing is a complex process driven by the viewers' program affinity, motives, interpersonal interaction, and the perceived media characteristics of alternative platforms. The social television viewing behavior also has a positive influence on loyalty to television programs, time-shifted viewing, and product purchase intention. The implications of these findings and recommendations for future research are discussed.
\end{abstract}

\section{Keywords}

mobile media; second screen platforms; social TV; viewer behavior

\section{Issue}

This article is part of the issue "Emerging Technologies in Journalism and Media: International Perspectives on Their Nature and Impact", edited by John Pavlik (Rutgers University, USA).

(C) 2019 by the author; licensee Cogitatio (Lisbon, Portugal). This article is licensed under a Creative Commons Attribution 4.0 International License (CC BY).

\section{Introduction}

As mobile devices proliferate through adoption of smartphones, tablets, and laptop computers, today's audiences are increasingly involved with television content through a "second screen" platform. In particular, mobile enhancement apps allow audiences to remotely comment and share their favorite shows. Social media create a new and powerful "backchannel", fueling the renaissance of live broadcasts. Mobile and tablet devices empower viewers to experience television whenever and wherever they want (Proulx \& Shepatin, 2012). All these developments have significantly invigorated the social nature of television viewing-social television viewing - the use of online apps and mobile devices to promote communication and social interaction related to television content. The emerging pattern of social television viewing is meaningful for program producers, broadcasters, and advertisers in their justification of investment in content, retaining and acquiring viewers, enhancing brand affinity and program loyalty, as well as identifying and marketing to the most valuable audi- ences. In light of the significance of social television viewing, this study aims to identify major exploratory factors of social television viewing from the perspectives of media content, media platforms, and audience attributes. This study further investigates the impacts of this process on program loyalty, time-shifted viewing, and product purchase likelihood.

\section{Literature Review}

\subsection{Social Television Viewing and Second Screening}

The emerging pattern of social television viewing through portable devices and social media platforms represents the ongoing convergence between mass and interpersonal communication (Perloff, 2015). Social television viewers use "communication technologies to connect with their friends and family, even when they are not watching the same screen" (Bellman, Robinson, Wooley, \& Varan, 2017, p. 73). Recent studies on social television are focused on the motives and personality characteristics of social television users (Cohen \& 
Lancaster, 2014; Guo, 2018; Guo \& Chan-Olmsted, 2015; Han \& Lee, 2014), television-related contents that are posted on various social platforms (Wohn \& Na, 2011), and the media effects of social television interactions on talent show content and program protagonists (Winter, Krämer, Benninghoff, \& Gallus, 2018).

Second screening, a similar concept with social television, describes that second screeners use digital devices (e.g., smart phones, tablets, or laptop computers) while watching television to access the Internet and social media platforms in order to obtain more information about or discuss the program they are watching (Zúñiga, GarciaPerdomo, \& McGregor, 2015). In the context of news consumption, second screening has been widely used by audiences during breaking news, live coverage, political debates, and online political participation (Giglietto \& Selva, 2014; Zúñiga et al., 2015).

Drawing upon previous studies on social television and second screening, this study defines social television viewing as the degree of intensity or types of connections that audiences develop with television content through online or mobile apps via second screen platforms. Second screen platforms here refer to mobile devices (e.g., smartphones, tablets, and laptop computers) that allow television viewers to interact with television content through the Internet and enhancement apps. Note that the term "television content" is defined broadly in this study, including the program content itself, characters or celebrities in the show, and related staff such as writers, directors, or producers, etc.

\subsection{Program Affinity, Involvement, and Genre Preference}

Affinity, defined as the level of importance one attaches to a medium or media content, has received considerable research attention in broadcasting and electronic media (Rubin, 2009). Rubin and Perse (1987a) measured television program affinity as the perceived importance of watching favorite television programs in audiences' daily lives. Affinity was found to be associated with diverse media use behavior and viewing motives (Haridakis \& Hanson, 2009). When examining one of the most popular social media platforms, YouTube, Haridakis and Hanson (2009) included affinity as one of a range of independent variables predicting such viewing behavior as co-viewing videos on YouTube and sharing videos with others.

Rubin and Perse (1987a, 1987b) categorized viewer involvement with soap operas or television news as affective involvement, cognitive involvement, and behavioral involvement. An involved television viewer may feel affect toward those in need on the show (i.e., affective involvement), consider the messages of the show (i.e., cognitive involvement), and talk about the show with others (i.e., behavioral involvement) during and after the exposure. In the case of reality programming, Hall (2009) proposed audience involvement as a three-dimensional con- struct to capture the current reality program consumption in a cross-media environment. Hall's dimensions include social involvement, cognitive involvement, and online involvement.

Genre preference refers to television viewers' predisposed liking of one specific program type or genre among a set of available program types or genres (e.g., soap opera, sports, drama, news, etc.) (Youn, 1994). Scholars and industry practitioners have previously concluded that television genre is an important predictor in viewing choice because the industry relies heavily on imitation (Bielby \& Bielby, 1994). Conventional program types, such as drama, sitcom, and so on, bear systematic relationships to program preferences (Geerts, Cesar, \& Bulterman, 2008). The preferences of different types of content could stimulate diverse social viewing experiences and communication patterns surrounding programs. For example, genre preferences can impact the way viewers talk, chat, or interact with each other while watching television or afterwards (Geerts et al., 2008). Sports programming is often cited as a genre best suited for stimulating social interaction. Other types of content such as cooking programs and movies also present this type of sociability (Harrison \& Amento, 2007). Some genres have been shown to be motivators of viewer engagement experiences such as sharing these program videos or viewing experiences with others. Thus, the following research questions are proposed:

RQ1: How is program affinity related to social television viewing via second-screen platforms?

RQ2: How is program involvement related to social television viewing via second-screen platforms?

RQ3: How is program genre preference related to social television viewing via second-screen platforms?

\subsection{Compatibility, Perceived Ease of Use, and Convenience}

Given the innovative attributes of mobile devices like smartphones, innovation diffusion theory offers a useful heuristic framework to investigate how individual audiences use mobile second screen platforms to engage with television content. Rogers (2003) conceptualized the perceived characteristics of an innovation as relative advantage, compatibility, complexity, trialability, and observability. Compatibility is defined as "the degree to which the adoption of a technology is compatible with existing values, past experiences, and needs of potential adopters" (p. 15). Thus, compatibility may refer to compatibility with the values or norms of the potential adopters or it may imply congruence with existing practices of the adopters (Tornatzky \& Klein, 1982). In Tornatzky and Klein's (1982) meta-analysis of innovation adoption, the authors discovered that an innovation is more likely to be adopted when it is compatible with an individual's job responsibility and value system. Additionally, prior innovation diffusion research found that com- 
patibility is salient in predicting the adoption of a range of new communication technologies (Chen, Gillenson, \& Sherrell, 2002).

The present study adopts perceived ease of use from the theory of technology acceptance as the second variable to predict the intent to use second screen platforms to engage with television content. Perceived ease of use is defined as "the degree to which a person believes that using a particular system would be free of effort" (Davis, 1989, p. 320). Prior studies showed that perceived ease of use has significant effects on user's enjoyment of cell phone usage (Kwon \& Chidambaram, 2000), online learning systems adoption (Saade \& Bahli, 2005), and mobile Internet applications acceptance (Cheong \& Park, 2005). The above research suggests that audiences' perceived ease of use of relatively new online communication systems like social media and enhancement apps would be related to their adoption for interaction with media content.

To better understand social television viewing through mobile second screen devices, this study includes perceived convenience of these mobile platforms as the third predictive variable. From marketing perspectives, convenience is defined by the time and effort consumers use in purchasing a product, or as a characteristic or attribute of a product (Berry, Seiders, \& Grewal, 2002). Time-related consumer research includes studies of time allocation, temporal orientation and perception, and cultural influence (Gross \& Sheth, 1989). Consumers' energy expenditures are examined from the perspectives of physical and emotional effort (Bettman, Johnson, \& Payne, 1990). Consumer behavior research revealed a significant correlation between individual differences and perceptions of required effort. Papacharissi and Rubin (2000) found that convenience of Internet use is significantly predictive of the duration or length of overall Internet usage. Moreover, Ko, Cho and Roberts (2005) suggested that consumers who have high information, convenience, and or/social interaction motivations for using the Internet tend to stay at a website longer to satisfy their needs. Thus, the following research questions are proposed:

RQ4: How is the perceived compatibility of secondscreen platforms related to social television viewing? RQ5: How is the perceived ease of use of secondscreen platforms related to social television viewing? RQ6: How is the perceived convenience of secondscreen platforms related to social television viewing?

\subsection{User Motives, Audience Innovativeness, and Personal Social Characteristics}

Traditional television viewing motives found in prior studies include habit, relaxation, companionship, passing time, information/learning, arousal, social interaction, escape, and entertainment as major drivers (Ru- bin \& Perse, 1987a, 1987b). For watching television content on the Internet (e.g., streaming video or webcasts), Lin (2001) found that entertainment appears to be less potent than the other two motives, information learning and escape/interaction, when examining online services adoption. However, with further exploration of webcasting adoption at a later time, the author concluded that entertainment plays a more critical role than news and information (Lin, 2004, 2006). Furthermore, audience motives are found to predict various viewing activities (Rubin \& Perse, 1987a, 1987b). The more strongly viewers are motivated, the more actively they engage in various audience activities before viewing (e.g., viewing intention), during viewing (e.g., attention and involvement), and post-viewing (e.g., discussion) (Lin, 1993). In addition, more salient viewing motivations, especially exciting entertainment and social utility, are found to be related to parasocial interaction, post-viewing cognition, and post-viewing discussion in the soap opera consumption context (Rubin \& Perse, 1987b).

Prior studies have indicated that alternative video platforms and traditional television viewing share a majority of motives such as entertainment, information, diversion, personal communications, and passing time (Guo \& Chan-Olmsted, 2015; Lin, 2004, 2006). However, due to other innate media characteristics associated with the Internet and its online apps, there are additional motives involved with these mobile devices, such as convenience, immediate access, and social interaction. The current study therefore synthesizes various motives for traditional television viewing, Internet use, and new media technologies to assess the social and physiological origins of social television viewing experiences, and poses the following research question:

RQ7: What user motives are related to social television viewing via second-screen platforms?

Audience members' personality traits regarding an innovation like new media technologies could also help predict how they might use second screens to engage with television content. In the domain of information technology, Agarwal and Prasad (1998) defined personal innovativeness as "the willingness of an individual to try out any new information technology" (p. 206). The individual's innovativeness trait is purported to "contribute to his or her cognitive response towards making an innovation adoption decision" (Lin, 2004, p. 447). Midgley and Dowling (1978) found that both innate innovativeness (the social-cognitive foundation) and actualized innovativeness (the social-situational basis) of an individual's personality traits are associated with the adoption of an innovation. The degree of innovativeness, noveltyseeking, and creative ability displayed in an individual's personality traits could single out those who have a greater propensity for early adoption of an innovation (Hirschman, 1980). Prior studies on Web-based technology adoption generally support the effects of personal in- 
novativeness on innovation adoption (Busselle, Reagan, Pinkleton, \& Jackson, 1999). Lin revealed that an individual's innovativeness attribute is a significant predictor for personal computer adoption (1998) and webcasting adoption (2004). Sun, Youn, Wu, and Kuntaraporn (2006) concluded that innovativeness is an important predictor of online social activities such as forwarding content and chatting with others. More importantly, one relevant study that focused on the social media platform, YouTube, showed that personal innovativeness predicts viewing and sharing of video in the content sharing community website (Haridakis \& Hanson, 2009). Therefore:

RQ8: How is audience innovativeness related to social television viewing via second-screen platforms?

As suggested in the uses and gratifications approach, media compete with other forms of communication or functional alternatives for a finite amount of time among limited audiences (Kaye \& Johnson, 2003; Rubin, 2009). The relationship between media and audience is therefore moderated by people's social and psychological circumstances, including lifestyle, life position, and personality. Offline activities like interpersonal interaction and social activities are suggested to play a role in online media use behavior (DiMaggio, Hargittai, Neuman, \& Robinson, 2001). Papacharissi and Rubin (2000) found that the greater satisfaction with personal interaction, such as face-to-face communication, people have, the more likely they are to use the Internet for information purposes; whereas those who are not satisfied with faceto-face interaction tend to use the Internet for interpersonal interaction in the virtual world. In the social media context, Haridakis and Hanson (2009) concluded from their empirical study that socially active audiences, particularly those watching for purposes of social interaction and co-viewing, use YouTube as a way of sharing online activities with family, friends and persons with whom they have existing social ties. Accordingly, second screeners' social activities and interpersonal interactions are hypothesized to be salient when using online apps or social media to engage with television content. Thus, this investigation proposes the following research question:

RQ9: How are audiences' social characteristics (i.e., interpersonal interaction and social activities) related to social television viewing via second-screen platforms?

\subsection{Program Loyalty, Time-shifted Viewing, and Product Purchase Likelihood}

Television program loyalty is centered on behavioral and attitudinal aspects of television viewers' commitment to certain preferred television programs. Brosius, Wober and Weimann (1992) defined television viewer loyalty along four dimensions: "(a) general loyalty to watching television, (b) channel (or network) loyalty, (c) types of program loyalty, and (d) specific program loyalty" (pp. 323-324). Research from academia and industry suggests audiences' increasingly cross-platform, multitasking media consumption patterns would help promote program loyalty. When investigating the relationship of cross-media usage with television viewer loyalty, $\mathrm{Ha}$ and Chan-Olmsted (2004) assessed the use of enhanced features on television websites such as online video streaming and message boards, concluding that the increase in the number of website features used positively predicts viewer loyalty (i.e., attitudinal loyalty). Lu and Lo (2007) further reported that television audience satisfactionone element of viewer engagement-strongly predicts repeat viewing intention (i.e., behavioral loyalty).

Time-shifted viewing refers to using digital video recorders (DVRs) to record programs for later viewer and accessing online video services to watch programs scheduled at inconvenient times. Prior research suggested viewing engagement or involvement has much impact on media use and effects, influencing the satisfaction that people receive from media use (Levey \& Windahl, 1984), and subsequent planned media exposure (Rubin \& Perse, 1987a). Following previous research on viewer engagement and audience satisfaction (Lin, 1993; Perse \& Rubin, 1988), the current study posits that audiences' viewing behavior is a temporal gratification-seeking process. The author expects strongly motivated viewers to be actively engaged in social television activities throughout the viewing process, and thus involved with more time-shifted viewing afterwards.

The eventual impact of social television viewing on purchase behavior is a chief consideration of advertisers and marketers. Kilger and Romer (2007) proposed that media engagement, advertising engagement, and brand engagement jointly impact consumers' product purchase intention. When further investigating a set of dimensions of engagement with three media channels (i.e., television, magazines, and the Internet), the authors revealed that there is evidence of a strong relationship between engagement in the media vehicle and the likelihood of purchasing a product advertised within that media vehicle (Kilger \& Romer, 2007). Ha and Chan-Olmsted (2001) suggested that there are two types of merchandise available on television networking sites: fan-based items and non-fan-based items. The authors noted that the more television website visitors are exposed to enhanced television features; the more likely they are to show an interest in buying products that have been advertised in the network shows or on the websites. Thus, the corresponding research questions are proposed:

RQ10: How is social television viewing via secondscreen platforms related to viewers' program loyalty? RQ11: How is social television viewing via secondscreen platforms related to viewers' time-shifted viewing?

RQ12: How is social television viewing via secondscreen platforms related to viewers' product purchase likelihood? 


\section{Method}

\subsection{Procedures}

Two online consumer panels of 1,010 second screen users were sampled to complete the two-stage research plan: pilot test and main test. The pilot test offered a theoretical rationale for the proposed social viewing construct; the main test was conducted to confirm the scale and test its predictors and consequences by surveying another online consumer panel with 801 qualified respondents. Both panels were managed by a U.S. research company uSamp, using an online survey instrument facilitated by the Qualtrics software. uSamp is a leading online market research company that provides opt-in consumer panels globally with over twelve million online participants. Such consumer panels have been commonly used in market research to investigate consumer behavior toward products and services (Sultan, 2002). The researcher specified a general sample frame as the second screen users over eighteen years old with a range of ages and demographics.

\subsection{Television Program Sample}

The main test consisted of twenty television programs delivered by major broadcast and cable networks ${ }^{1}$. According to the pilot test results, five most popular program genres were selected: sport events, dramas, reality shows, news, and sitcoms. Considering that second screen television viewing incorporates various social media activities, specific program titles were selected by referring to two online database, Social Television Charts ${ }^{2}$ and Nielsen Twitter TV Ratings. The first database is a comprehensive television index that incorporates multiple social media activities as public Facebook posts, Twitter mentions, GetGlue check-ins, and Miso checkins. Nielsen Twitter TV ratings list top-ranked television shows weekly based on audiences' Twitter activities.

\subsection{Participants}

There were 800 respondents who completed the demographic information in the main test and 209 respondents in the pilot test. The average age in the main test was $39.3(S D=13.65)$, a slightly younger sample than in the pretest (mean age $40.41, S D=13.96$ ). Males ( $n=375$ ) accounted for $46.9 \%$ while females totaled
$53.1 \%$ ( $n=425$ ) in the main test. The gender structure of the pilot test was shown to be similar with the main test (male $=48.3 \%$, female $=51.7$ ). Caucasians accounted for $80 \%$, followed by African-Americans (8.2\%), Latino/Latina/Hispanics (5.0\%), and Asians (4.1\%).

\section{Measures}

\subsection{Social Television Viewing}

To operationalize the construct of social television viewing, this study uses fourteen items to measure the different manifestations of how television audiences use second screen platforms and mobile apps to engage with television content ${ }^{3}$. The fourteen social engagement items measured the nature of how television audiences take advantage of the capability of second screen platforms to develop a deep, perpetual engagement with television program content and related information, characters or celebrities, and other television viewers through a five-point Likert scale $(1=$ not at all, 5 = extremely).

\subsection{Program Affinity}

Two sets of measures-the Television Affinity Scale (Rubin, 1983) and program affinity (Rubin \& Perse, 1987a, 1987b) - were adapted to tap respondents' attitudes about their favorite television shows with which they interacted using second screen platforms. The three-item affinity scale was used to assess how important the viewing was and how much affinity the respondents felt watching their favorite shows using statements such as "Watching the program is one of the most important things I do each day or each week". The respondents were asked to indicate their level of agreement with each of the statements using a five-point Likert scale ( 1 = strongly disagree, 5 = strongly agree).

\subsection{Program Involvement}

To assess the personal cognitive, affective, and functional dimensions of involvement with a particular television program, four semantic differential items were applied on a five-point scale, including irrelevant/relevant, means nothing to me/means a lot to me, doesn't matter/matters to me, and nonessential/essential (Park \& McClung, 1986).

\footnotetext{
${ }^{1}$ The list of programs: NCIS, Criminal Minds, Sons of Anarchy, Scandal, Glee, The Walking Dead, Break Bad, Pretty Little Liars, Supernatural, American Horror Story: Coven, Law \& Order, Big Brother, The Voice, Survivor, Dancing with the Stars, Real Housewives Series, Duck Dynasty, and The Big Bang Theory. 2 http://trendrr.tv

${ }^{3}$ The 14 social television viewing items are: I have used apps or the Internet to find program-related info and updates. I have used apps and the Internet to check biography and background of characters/players of the program. I have used broadcast/cable network websites to watch the program through my media devices. I have used the show-specific apps to watch the program through my media devices. I have used broadcast/cable network apps to watch the program through my media devices. I have read the program tweets (including actors, writers, producers, etc.,) in Twitter. I have written or commented on the program tweets (including actors, writers, producers, etc.) in Twitter. I have interacted with my friends about the program through my personal Facebook page. I have written or commented on the program posts in Facebook. I have indicated to "like" the program in Facebook. I have blocked out things around me while watching the program through my media devices. I have lost myself while watching the program through my media devices. I have avoided interacting with others while watching the program through my media devices. I have lost track of time while watching the program through my media devices.
} 


\subsection{Program Genre Preference}

The current study uses the five popular genres for second screen use for social viewing (commenting, posting, watching, or reading about). They are sport events, news, reality, dramas, and sitcoms. In addition, based on the program that each respondent selected in the main test, this study evaluated participants' overall preference for the program genre of the identified show. Some television program genres studies used the amount of attention paid in watching shows of particular genres as the basis for viewer genre preference (Hawkins, et. al., 2001; Moyer-Guséé, 2010), while others focused on audiences' enjoyment experience or watching likelihood (MoyerGuséé, 2010). Thus, we adapted two statements focused on viewing attention and enjoyment experience using a five-point Likert scale ( $1=$ not at all, $5=$ extremely).

\subsection{Compatibility}

Perceived compatibility measures "the degree to which the adoption of a technology is compatible with existing values, past experiences, and needs of potential adopters" (Rogers, 2003, p. 15). This study used three items from Tornataky and Klein (1982), Chen et al. (2002), and Chan-Olmsted and Chang (2006). A five-point Likert scale was used to evaluate respondents' level of agreement with each of the statements assessing the variable of perceived compatibility with second screen platforms in general.

\subsection{Perceived Ease of Use}

The construct of perceived ease of use measures "the degree to which an individual believes that using a particular system would be free of physical and mental efforts" (Davis, 1989, p. 323). Three items were adapted from prior studies to assess perceived ease of use of the second screen devices in terms of learning, skillfulness, and usage through a five-point Likert scale ( 1 = strongly disagree, 5 = strongly agree) (Davis, Bagozzi, $\&$ Warshaw, 1989).

\subsection{Convenience}

Convenience measures the degree to which a secondscreen user perceives that engaging with mobile platforms to interact with television content is free of time and location limits. Adapted from previous scales (Berry et al. , 2002; Ko et al., 2005), the authors formulated four items to measure the construct through a five-point Likert scale ( 1 = strongly disagree, $5=$ strongly agree), including "The media device(s) or mobile apps allow me to interact with television shows whenever I want", "I value the ability of the media device(s) or mobile apps to interact with television shows from the comfort of home".

\subsection{User Motives}

The social and psychological needs of second screeners to interact with television content are mainly driven by the television program itself, the Internet, and diverse online applications. Therefore, the current study compiled forty-nine motives behind television viewing (Rubin, 1983), Internet use (Papacharissi \& Rubin, 2000), and YouTube video viewing (Haridakis \& Hanson, 2009). The final set of the 49-item scale represented a range of motives identified by prior studies, including relaxation, companionship, habit, passing time, entertainment, social interaction, information seeking, arousal, escape, convenience, and personal utility. This study asked the respondents to indicate how much each of the motive statements was like their own reasons for using second screen devices to engage with television content through a five-point Likert scale ( 1 = strongly disagree, 5 = strongly agree).

\subsection{Audience Innovativeness}

This study adapted Goldsmith and Hofacker's (1991) innovativeness scale to assess audiences' innovativeness with social media systems. The domain-specific scale reflected the tendency to learn about and adopt innovations within a specific domain of interest, which was found to be a valid and reliable measure for different innovations in transnational settings (Goldsmith \& Flynn, 1992). The present study modified the six items to reflect the multi-screen social television viewing context and asked respondents to rate their level of agreement with each statement using a five-point Likert scale, including their perceptions and behaviors.

\subsection{Social Characteristics}

Adapted from the previous studies on contextual age scales (Rubin, 1986; Rubin \& Rubin, 1986, 1989), the present study measured two dimensions of social characteristics of the respondents, including the level of interpersonal interaction and offline social activities. The respondents rated their level of agreement $(1=$ strongly disagree, 5 = strongly agree) with four statements assessing their interpersonal interaction (e.g., "I have ample opportunity for conversations with others"), and five statements to measure their offline social activity (e.g., "I often participate in the meetings or activities of clubs, lodges, recreation centers, churches, or other organizations").

\subsection{Program Loyalty}

Program loyalty, operationalized as attitudinal loyalty, was focused on stated recommendations, preferences, or probabilities of viewing by the audiences, thus emphasizing the cognitive element of program loyalty. The three items were stated as "recommending the program 
to others", "thinking of himself/herself as a loyal viewer of the show", and "willing to watch the show rather than other programs".

\subsection{Time-Shifted Viewing}

This study measures time-shifted viewing through two popular platforms: DVR recording and online video streaming services such as Netflix, Hulu Plus, and Amazon Prime. The first statement asked the participants if they had used DVR or online video services to catch up on past episodes of the show they missed over the past month. The second item measured the time-shifted viewing intention of the show in the future among the respondents.

\subsection{Product Purchase Likelihood}

This study examined respondents' purchase likelihood of products from their program's official website. There are usually two types of merchandise available: fan-based items and non-fan-based items. The fan-based items are items relevant to the networks or its shows and stars, while non fan-based items are products of the advertisers on the networks (Ha \& Chan-Olmsted, 2004). Viewers' purchase intentions toward the two types of products were discovered by three items using a five-point Likert scale ( $1=$ definitely not, $5=$ definitely $)$ to assess whether the respondents would be more likely to buy memorabilia.

\section{Results}

\subsection{Motivations behind Social Television Viewing via Second-Screen Platforms}

RQ7 asked what motives audiences have for using second screen platforms to engage with television content. To answer the research question, the exploratory factor analysis (EFA) procedure was carried out to analyze the forty-nine motive statements. The factor analyses were performed on a polychoric correlation matrix using the maximum likelihood with mean and variance estimation procedure through an oblique Geomin rotation by Mplus program. By analyzing the screen plots and goodness of fit indices, a series of models was estimated and compared. A ten-factor model showed the best fit $\left(\chi^{2}=711.369, d f=290, p=.000 ; \mathrm{CFI}=.982\right.$, $\mathrm{TLI}=.964, \mathrm{RMSEA}=.042, \mathrm{SRMR}=.011)$. Thus, this study concluded that the ten-factor solution best describes the motive test.

The EFA yielded ten motives behind social engagement behavior, corresponding to previous television viewing motives (Rubin, 1983), Internet use motives (Papacharissi \& Rubin, 2000), and YouTube video viewing motives (Haridakis \& Hanson, 2009). The first factor, relaxation, was comprised of three items related to a pleasant rest and relaxation-driven motivation. The second factor, companionship, described relief from aloneness as a reason for social engagement behavior. The third factor, passing time, described how television audiences use the second screens to interact with television content out of habit and to occupy time. The fourth factor, entertainment, was comprised of three items illustrating the experience of social engagement with television content for amusement and enjoyment. The fifth factor, interpersonal connection, was comprised of six items related to using mobile devices to be involved with television programs that measured belonging, inclusion, affection, social interaction, and expressive needs. The sixth factor, learning, reflected learning unknown and useful things as a motivation for social engagement behavior. The seventh and eighth factors contained three items describing the arousal and escape motives. The ninth factor, information, explained how the social engagement experience is derived from being informed. The last factor, access, measured the use of the second screens to access television content, because it is easier and a novel way of searching for information and keeping up with current issues.

Based on the motive factor structure, the author conducted reliability testing for each motivation using Cronbach's coefficient alpha. The acceptable value for Cronbach's coefficient is above .70 (Kline, 2011). The Cronbach's coefficient alpha values for the ten motives behind using mobile devices to engage with television content ranged from .872 to .937 , suggesting that the ten motivation scales are reliable measures. Table 1 presents the descriptive statistics, Cronbach's coefficient alpha, and correlations for the ten motive factors.

\subsection{Antecedents to Social Television Viewing via Second-Screen Platforms}

Significant antecedents to social television viewing included program affinity $(\gamma=.464, p<.01)$, ease of use $(\gamma=.110, p<.05)$, compatibility $(\gamma=.123, p<.1)$, convenience $(\gamma=.132, p<.1)$, the motive of interpersonal connection $(\gamma=.228, p<.01)$ and arousal $(\gamma=.126$, $p<.05)$, as well as interpersonal interaction $(\gamma=.109$, $p<.05)$. The results indicated that program-related variables like program affinity are positively associated with social television viewing behavior. Viewers who possess strong affinity toward the program and perceive it as more important and relevant in their daily lives tend to actively utilize the second screens to interact with television content.

Furthermore, media characteristics of second screen platforms, such as perceived ease of use, compatibility, and convenience, play an important role in predicting the social engagement experience with television. The results suggested that superior features and functions embedded in mobile devices like smartphones and tablets significantly promote users' social television viewing activities, because these second screen devices are easy to use, convenient to possess and access, and compatible with their life styles. 
Table 1. Descriptive statistics, internal consistency values, and intercorrelations for motive factors.

\begin{tabular}{|c|c|c|c|c|c|c|c|c|c|c|c|c|c|c|c|}
\hline Factor & Motive & $\begin{array}{l}\text { No. of } \\
\text { Items }\end{array}$ & Mean & $S D$ & Alpha & 1 & 2 & 3 & 4 & 5 & 6 & 7 & 8 & 9 & 10 \\
\hline 1 & Relaxation & 3 & 3.64 & .95 & .937 & 1.000 & & & & & & & & & \\
\hline 2 & Companionship & 3 & 2.95 & .99 & .911 & $.380 *$ & 1.000 & & & & & & & & \\
\hline 3 & Pass Time & 3 & 3.38 & 1.03 & .897 & $.274^{*}$ & $.479 *$ & 1.000 & & & & & & & \\
\hline 4 & Entertainment & 3 & 4.09 & .72 & .900 & $.590 *$ & $.212^{*}$ & $.269 *$ & 1.000 & & & & & & \\
\hline 5 & $\begin{array}{l}\text { Interpersonal } \\
\text { Connection }\end{array}$ & 6 & 3.33 & .96 & .923 & $.499 *$ & $.482^{*}$ & $.301^{*}$ & $.394^{*}$ & 1.000 & & & & & \\
\hline 6 & Learning & 3 & 3.05 & 1.10 & .901 & $.433^{*}$ & $.523 *$ & $.248^{*}$ & $.250 *$ & $.591^{*}$ & 1.000 & & & & \\
\hline 7 & Arousal & 3 & 3.44 & 1.07 & .914 & $.552 *$ & $.369 *$ & $.236^{*}$ & $.585^{*}$ & $.545^{*}$ & $.539^{*}$ & 1.000 & & & \\
\hline 8 & Escape & 3 & 3.10 & 1.10 & .872 & $.445^{*}$ & $.597^{*}$ & $.434^{*}$ & $.317^{*}$ & $.535^{*}$ & $.554^{*}$ & $.522^{*}$ & 1.000 & & \\
\hline 9 & Information & 3 & 3.92 & .82 & .889 & $.310^{*}$ & $.181^{*}$ & $.312^{*}$ & $.408^{*}$ & $.352^{*}$ & $.252^{*}$ & $.264^{*}$ & $.279 *$ & 1.000 & \\
\hline 10 & Access & 3 & 3.76 & .88 & .908 & $.356^{*}$ & $.298^{*}$ & $.278^{*}$ & $.376^{*}$ & $.32 *$ & $.406^{*}$ & $.376^{*}$ & $.318^{*}$ & $.674^{*}$ & 1.000 \\
\hline
\end{tabular}

Note: alpha $=$ Cronbach's alpha; $* p<.05$ (two-tailed). $\mathrm{n}=805$ 
Interpersonal interaction rather than offline social activity appeared to be significantly predictive of the social engagement experience. The results suggested that even though individuals have ample opportunities to interpersonally communicate with friends, family, relatives, or others in their offline lives, they desired to further engage in their communication with other audience members with different levels of social activities "surrounded" or "submerged" in a television program in the virtual space. By contrast, offline social activity did not exhibit any influences on social viewing tendencies.

In terms of motivations for social viewing behavior, the results showed that interpersonal connection and arousal are two salient positive predictors. It seems people driven by interpersonal connection and arousal needs tend to be more likely to use second screens to interact with television content. In summary, perceived attributes of second screen platforms, program affinity, the audiences' interpersonal connection and arousal motivations, and their interpersonal interaction attributes appeared to be significant predictors of the social television viewing experience. The causal relationships are presented in Table 2.

\subsection{Consequences of Social Television Viewing via Second-Screen Platforms}

RQ 10 through RQ12 pertained to possible consequences of social viewing activities, including program loyalty, time-shifted viewing, and product purchase likelihood. As shown in Table 3, social television viewing was a significant and substantial predictor for all three postviewing activities. Social engagement behavior demonstrated positively predictive power on all proposed consequences: program loyalty $(\gamma=.457, p<.01)$, timeshifted viewing $(\gamma=.613, p<.01)$, and product purchase

Table 2. Antecedents to social television viewing via second-screen platforms.

\begin{tabular}{llcr}
\hline & & \multicolumn{2}{c}{$\begin{array}{c}\text { Social Engagement } \\
\text { Standardized path coefficient }\end{array}$} \\
\hline RQ1 & Pntecedents &. $\mathbf{4 6 4 * * *}$ & .070 \\
RQ2 & Program affinity & -.080 & .055 \\
RQ3 & Program involvement & .012 & .031 \\
RQ4 & Genre preference & $.123 *$ & .064 \\
RQ5 & Compatibility & $.110^{* *}$ & .052 \\
RQ6 & Perceived ease of use & $.132 *$ & .068 \\
RQ7 & Convenience & .001 & .046 \\
RQ7 & Relaxation & .005 & .055 \\
RQ7 & Companionship & .026 & .042 \\
RQ7 & Pass time & -.019 & .057 \\
RQ7 & Entertainment & $.228 * * *$ & .065 \\
RQ7 & Personal Utility & -.036 & .063 \\
RQ7 & Learning & $.126 * *$ & .058 \\
RQ7 & Arousal & -.010 & .055 \\
RQ7 & Escape & -.024 & .052 \\
RQ7 & Information & -.066 & .061 \\
RQ8 & Access & $.117 *$ & .076 \\
RQ9 & Innovativeness & $.109 * *$ & .049 \\
RQ9 & Interpersonal interaction & .061 & .057 \\
\hline
\end{tabular}

Note: ${ }^{*} p<0.1,{ }^{*} p<0.05, * * * p<0.01$ (two-tailed). The goodness of fit indices: $\chi^{2}=46119.29(d f=3916, p<.001)$; CFI $=.944$, $\mathrm{TLI}=.939, \mathrm{RMSEA}=.029, \mathrm{SRMR}=.047$.

Table 3. Consequences of social engagement.

\begin{tabular}{llll}
\hline & Consequences & Social Engagement & \\
\hline \multirow{2}{*}{ RQ10 } & Program Loyalty & Standardized path coefficient &. $\mathbf{4 5 7 * * *}$ \\
\hline \multirow{2}{*}{ RQ11 } & Time-shifted Viewing & SE & .048 \\
\hline \multirow{2}{*}{ RQ12 } & & Standardized path coefficient & $.613^{* * *}$ \\
& Product Purchase Likelihood & SE & .034 \\
\hline
\end{tabular}

Note: ${ }^{*} p<0.1,{ }^{* *} p<0.05,{ }^{* * *} p<0.01$ (two-tailed). The goodness of fit indices: $\chi^{2}=46119.29(d f=3916, p<.001) ; \mathrm{CFI}=.944$, $\mathrm{TLI}=.939, \mathrm{RMSEA}=.029, \mathrm{SRMR}=.047$. 
likelihood $(\gamma=.663, p<.01)$. The results appear to provide definite support for the economic importance of social television viewing.

\section{Discussion and Implications}

This study presents an active audience behavioral model, which integrates the theory of television program choice, technology acceptance model, innovation diffusion theory, and the uses and gratifications approach. The main purpose of the integration is to offer a comprehensive framework to better understand why television audiences are actively involved with various second screen platforms to connect with television content, and what the possible outcomes of this social viewing experience are. The first benefit of the integrated approach for active audience behavior is that it provides a comprehensive picture to better understand the social television engagement process. As suggested in the audience behaviorist research tradition, audiences are variably active across several qualitative dimensions and along the temporal dimension before, during, and after media exposure (Rubin, 1987a, 1987b). Thus, the present study first approaches the multimedia television consumption pattern by validating the qualitative dimensions in social television viewing engagement. This study then examines the temporal dimension of before, during, and after the social television viewing behavior.

Another benefit of the integrated framework is that it presents a good basis for comparing the strengths and weaknesses of each theoretical branch that forms the active audience behavior model. Specifically, this investigation identifies three categories of explanatory factors to predict the social viewing experience from the perspectives of media content (i.e., perceptions of television programs), media channel (i.e., perceived characteristics of second screen platforms and enhancement apps), and media user (i.e., audience attributes). The predictive ability of each factor is tested and compared in predicting social television viewing patterns. At the same time, the predictive effects of social viewing on the following proposed consequences are evaluated, including program behavioral and attitudinal loyalty, time-shifted viewing, and product purchase likelihood. In particular, by assessing the strengths or weaknesses of different determinants, the current study could identify which predictors play more significant roles for social viewing behavior. Most importantly, the findings demonstrate that the social television engagement process is a composite result, which is determined by multiple components jointly under the integrated framework of active audience behavior.

Regarding the significant predictors of social engagement, this study identifies the following determinants: program affinity, perceived ease of use, compatibility, convenience, the motive of interpersonal connection and arousal, as well as the individual's interpersonal interaction attributes. Program affinity is strongly predic- tive of social engagement behavior. The findings here are indicative of the value of content, implying that "content is still king" in multi-screen television consumption environments. In the contemporary interactive video consumption environment, the definition of television content expands to a broader scope, including the core program and its ancillary information, the characters, celebrities, and other media persona of the program, and even content-related media activities. Accordingly, the deepest level of social engagement is driven by the quality of content, regardless of format and media platform. Thus, how to develop the best strategy to foster viewer affinity towards a television program becomes the most critical issue.

Regarding perceived media characteristics of the second screens, all proposed attributes such as perceived ease of use, convenience, and compatibility are found to be salient determinants of social viewing behavior. The results are not unexpected as the mobility and functionality delivered by these platforms empower television viewers. Ease of use and convenient access to television content suggest perceived characteristics of the second screens might become less pertinent as consumers become more technologically proficient with new devices. Therefore, the perceived compatibility of media devices and online enhancement apps will be more relevant to user lifestyles and value systems, playing a larger role in the social television adoption process. Moreover, it is interesting to note that many second screeners attach emotions or feelings with their mobile devices, representing emotional engagement with these companion devices. Particularly, in the social viewing context, second screeners tend to voice more emotional importance for phones than tablets or laptops-reflecting their role as an omnipresent extension of the self. It was not uncommon for the participants to describe their relationship with the smartphone as one of ambivalent dependency: "It's my life-everything's on there" and "We spend too much time on our phones".

Under the context of social television viewing through second screen devices, the audience dispositional factor, innovativeness, did not play a role in the social television viewing adoption. It might be attributed to the fact that smartphones and tablets have achieved mass-market acceptance, and mobile device ownership has progressed from leading edge and early technology adopters to those less motivated by innovative technologies. These individuals were found to have more traditional views on device use and do not necessarily adopt the same device use behavior as technology mavens (Loechner, 2013). Accordingly, in comparison to those media attributes soliciting curiosity, initiative, and demanding skills, social television viewers more value such characteristics delivered by their mobile devices as perceived ease of use, convenience, and compatible with their lifestyle. The findings here resonate with a latest industry survey, suggesting that all age groups of the U.S. adults are increasingly engaged in multitasking behavior 
while watching television; the growing trend is apparent across three defined categories of technology adopters based on their innovativeness (i.e., leading edge, early adopters, and proven technology) (Loechner, 2013).

The empirical validation of the predictive ability of interpersonal interaction to social engagement is particularly interesting. The predictive effect of interpersonal interaction is significant and positive on social viewing behavior. This discovery implies that audiences, who do have ample opportunities or are satisfied with their interpersonal communication, would still be inclined to utilize various online/mobile platforms to interact with media figures and other audience members related to their favorite shows. Social interaction between viewers and media figures is to some degree a type of parasocial interaction, in which viewers believe they know the media persona as they do a friend, treating the interaction as an interpersonal relationship. Thus, the empirical findings provide evidence in support of the social enhancement premise advanced in prior research, which states that extroverted and outgoing persons are motivated to add online contacts to their established large network of offline friends (Zywica \& Danowski, 2008). The findings here may challenge results from those previous studies based on media compensation hypotheses, suggesting that people who are less sociable and dissatisfied with face-to-face interaction are more likely to use media as compensation (e.g., Papacharissi \& Rubin, 2000).

This study found that two motives, i.e., interpersonal connection and arousal, are significantly predictive of social television engagement behavior. The social reason for interpersonal connection is intriguing because it highlights the socially interactive nature of television viewing facilitated by second screen devices. The underlying elements of interpersonal connection motives suggest that people who are using mobile devices and enhancement apps to be involved with television content are mainly driven by belonging, inclusion, affection, social interaction, and expressive needs. Through posting, sharing, feedback and recommendations, mobile devices and social media transcend time and space and create a space for conversations among viewers. The results again suggest social television is a means of communication and social interaction in the context of watching television or accessing television-related content, and support Askwith's (2007) and Russell, Norman, and Heckler's (2004a, 2004b) research regarding the social interaction nature of television viewing.

In addition, to investigate the predictive effects of social television viewing, this study further proposes three consequences of the process: program loyalty, timeshifted viewing, and product purchase likelihood. The social television viewing activities are found to have significant impacts on all proposed outcomes. The findings are consistent with prior research from academia and industry suggesting audiences' cross-platform, multitasking media consumption patterns help promote program loyalty (Ha \& Chan-Olmsted, 2004; Lu \& Lo, 2007), im- prove the likelihood of product purchase (Kilger \& Romer, 2007), and boost time-shifted viewing. Overall social viewing behavior bears the strongest positive relationship with the likelihood of purchasing products that have been advertised on the program's station and network websites. As suggested by prior study (e.g., Ha \& ChanOlmsted, 2004), however, it is still challenging for television managers who plan to utilize their website and online apps as a platform to conduct e-commerce due to audiences' general lower interests and experience in television e-commerce. Similarly, Lin and Cho (2010) examined the effects of television audiences' cross-media usage, discovering that cross-media involvement with televised programs could improve the program loyalty and further promote product purchase intention. However, the authors admitted that television e-commerce and interactive online product placement on the program's official website are still underutilized by the current online users (Lin \& Cho, 2010).

\section{Limitations}

This study offers valuable findings related to utilizing second screen platforms to engage with television content over time. However, there are several limitations that should be taken into account when evaluating and interpreting the conclusions. While the use of online consumer panels sampled from the online population helps enhance the external validity of the findings, these results should not be generalized to all online users or all television viewers. Given the research questions in this study necessitated the use of a purposive sample of online users who engage in second screen experiences related to television viewing, these findings are not necessarily applicable to all online consumers or all second screeners. Additionally, as discussed previously, this study identifies three major exploratory factors of social television viewing from the perspectives of media content, media platforms, and audience attributes. Thus, the theoretical and practical implications of this investigation also center on these aspects. There are other external factors such as program availability issues that might impact the adoption process. Therefore, it is necessary to take these external factors into account when interpreting the social television viewing process.

\section{Conflict of Interests}

The author declares no conflict of interests.

\section{References}

Agarwal, R., \& Prasad, J. (1998). A conceptual and operational definition of personal innovativeness in the domain of information technology. Information System Research, 9(2), 204-215.

Askwith, I. D. (2007). Television 2.0: Reconceptualizing TV as an engagement medium. Comparative 
Media Studies. Retrieved from http://cms.mit.edu/ research/theses/IvanAskwith2007.pdf

Bellman, S., Robinson, J. A., Wooley, B., \& Varan, D. (2017). The effects of social TV on television advertising effectiveness. Journal of Marketing Communications, 23(1), 73-91.

Berry, L. L., Seiders, K., \& Grewal, D. (2002). Understanding service convenience. Journal of Marketing, 66(3), 1-17.

Bettman, J. R., Johnson, E. J., \& Payne, J. W. (1990). A component analysis of cognitive effort in choice. Organizational Behavior and Human Decision Processes, 45(1), 111-139.

Bielby, W. T., \& Bielby, D. D. (1994). "All hits are flukes": Institutionalized decision making and the rhetoric of network prime-time program development. American Journal of Sociology, 99(5), 1287-1313.

Brosius, H. B., Wober, M., \& Weimann, G. (1992). The loyalty of television viewing: How consistent is TV viewing behavior? Journal of Broadcasting \& Electronic Media, 36(3), 321-335.

Busselle, R., Reagan, J., Pinkleton, B., \& Jackson, K. (1999). Factors affecting Internet use in a saturatedaccess population. Telematics \& Informatics, 16(1/2), 45-68.

Chan-Olmsted, S. M., \& Chang, B.-H. (2006). Audience knowledge, perceptions, and factors affecting the adoption intent terrestrial digital television. New $\mathrm{Me}$ dia \& Society, 8(5), 773-780.

Chen, L., Gillenson, M. L., \& Sherell, D. L. (2002). Enticing online consumers: Extended technology acceptance perspective. Information \& Management, 39(8), 705-719.

Cheong, J. H., \& Park, M. (2005). Mobile Internet acceptance in Korea. Internet Research, 12(5), 125-140.

Cohen, E. L., \& Lancaster, A. L. (2014). Individual differences in in-person and social media television coviewing: The role of emotional contagion, need to belong, and co-viewing orientation. Cyberpsychology, Behavior, and Social Networking, 17(8), 512-518.

Davis, F. D. (1989). Perceived usefulness, perceived ease of use, and end user acceptance of information technology. MIS Quarterly, 13(3), 319-339.

Davis, F. D., Bagozzi, R. P., \& Warshaw, P. R. (1989). User acceptance of computer technology: A comparative of two theoretical models. Management Science, 35(8), 982-1003.

DiMaggio, P., Hargittai, E., Neuman, W. R., \& Robinson, J. P. (2001). Social implications of the Internet. Annual Review of Sociology, 27(1), 307-336.

Geerts, D., Cesar, P., \& Bulterman, D. (2008). The implications of program genres for the design of social television systems. In Proceedings of the international conference on designing interactive user experiences for TV and video (UXTV 2008) (pp. 71-80). New York, NY: ACM.

Giglietto, F., \& Selva, D. (2014). Second screen and participation: A content analysis on a full season dataset of tweets. Journal of Communication, 64(2), 260-277.

Goldsmith, R. E., \& Flynn, L. R. (1992). Identifying innovators in consumer product market. European Journal of Marketing, 26(12), 42-55.

Goldsmith, R. E., \& Hofacker, C. F. (1991). Measuring consumer innovativeness. Journal of the Academy of Marketing Research, 19(3), 209-221.

Gross, B. L., \& Sheth, J. N. (1989). Time-oriented advertising: A content analysis of United States magazine advertising, 1890-1988. Journal of Marketing, 53(3), 76-83.

Guo, M. (2018). How television viewers use social media to engage with programming: The social engagement scale development and validation. Journal of Broadcasting \& Electronic Media, 62(2), 195-214.

Guo, M., \& Chan-Olmsted, S. M. (2015). Predictors of social television viewing: How perceived program, media, and audience characteristics affect social engagement with television programming. Journal of Broadcasting \& Electronic Media, 59(2), 240-258.

Ha, L., \& Chan-Olmsted, S. M. (2004). Cross-media use in electronic media: The role of cable television web sites in cable television network branding and viewership. Journal of Broadcasting \& Electronic Media, 48(4), 620-645.

Hall, A. (2009). Perception of the authenticity of reality programs and their relationships to audience involvement, enjoyment, and perceived learning. Journal of Broadcasting \& Electronic Media, 53(4), 515-531.

Han, E., \& Lee, S. W. (2014). Motivations for the complementary use of text-based media during linear TV viewing: An exploratory study. Computers in Human Behavior, 32(2), 235-243.

Haridakis, P., \& Hanson, G. (2009). Social interaction and co-viewing with YouTube: Blending mass communication reception and social connection. Journal of Broadcasting \& Electronic Media, 53(2), 317-335.

Harrison, C., \& Amento, B. (2007). Collaborate TV: Using asynchronous communication to make TV social again. Retrieved from http://www2.research.att. com/ brian/papers/2007EUROITV-CTV.pdf

Hawkins, R., Pingree, S., Hitchon, J., Gorham, B. W., Kannaovakun, P., Gillligan, E., ... . Schmidt, T. (2001). Predicting selection and activity in television genre viewing. Media Psychology, 3(2), 237-263.

Hirschman, E. C. (1980). Innovativeness, novelty seeking, and consumer creativity. Journal of Consumer Research, 7(3), 283-295.

Kaye, B., \& Johnson, T. (2003). From here to obscurity? Media substitution theory and traditional media in an on-line world. Journal of the American Society for Information Science \& Technology, 54(3), 264-274.

Kilger, M., \& Romer, E. (2007). Does measures of media engagement correlate with product purchase likelihood? Journal of Advertising Research, 47(3), 313-325.

Kline, R. B. (2011). Principles and practice of structural equation modeling (3rd ed.). New York, NY: The Guil- 
ford Press.

Ko, H., Cho, C., \& Roberts, M. S. (2005). Internet uses and gratifications: A structural equation model of interactive advertising. Journal of Advertising, 34(2), 57-70.

Kwon, H. S., \& Chidambaram, L. (2000). A test of the technology acceptance model: The case of cellular phone adoption. In Proceedings of the 33rd Hawaii international conference on system science (pp. 1-10). Maui, HI: IEEE Xplore.

Levy, M. R., \& Windahl, S. (1984). Audience activity and gratification: A conceptual clarification and exploration. Communication Research, 11(1), 51-78.

Lin, C. A. (1993). Modeling the gratification-seeking process of television viewing. Human Communication Research, 20(2), 224-244.

Lin, C. A. (2001). Audience attributes, media supplementation, and likely online service adoption. Mass Communication \& Society, 4(1), 19-38.

Lin, C. A. (2004). Webcasting adoption: Technology fluidity, user innovativeness, and media substitution. Journal of Broadcasting \& Electronic Media, 48(3), 446-465.

Lin, C. A. (2006). Predicting webcasting adoption via personal innovativeness and perceived utilities. Journal of Advertising Research, 46(2), 228-238.

Lin, J., \& Cho, C. (2010). Antecedents and consequences of cross-media usage: A study of a TV program's official web site. Journal of Broadcasting \& Electronic Media, 54(2), 316-336.

Loechner, J. (2013, December 6). Multitasking with TV and smartphones or tablets. Retrieved from http:// www.mediapost.com/publications/article/214548/ multitasking-with-tv-and-smartphones-or-tablets. html\#reply

Lu, X., \& Lo, H. (2007). Television audience satisfaction: Antecedents and consequences. Journal of Advertising Research, 47(3), 354-363.

Midgley, D. F., \& Dowling, G. R. (1978). Innovativeness: The concept and its measurement. Journal of Consumer Research, 4(4), 229-242.

Moyer-Guséé, E. (2010). Preference for television programs about sexual risk: The role of program genre and perceived message intent. Media Psychology, 13(2), 180-199.

Papacharissi, Z., \& Rubin, A. M. (2000). Predictors of Internet use. Journal of Broadcasting \& Electronic Media, 44(2), 175-196.

Park, C. W., \& McClung, G. W. (1986). The effect of TV program involvement on involvement with commercials. In R. J. Lutz (Ed.), Advances in consumer research (Vol. 13, pp. 544-548). Provo, UT: Association for Consumer Research.

Perloff, R. M. (2015). Mass communication research at the crossroads: Definitional issues and theoretical directions for mass and political communication scholarship in an age of online media. Mass Communication \& Society, 18(5), 531-556.

Perse, M. E., \& Rubin, M. A. (1988). Audience activity and satisfaction with favorite television soap opera. Journalism Quarterly, 65(2), 368-375.

Proulx, M. \& Shepatin, S. (2012). Social TV: How marketers can reach and engage audiences by connecting television to the web, social media, and mobile. Hoboken, NJ: John Willey \& Sons, Inc.

Rogers, E. M. (2003). Diffusion of innovations (5th ed.). New York, NY: The Free Press.

Rubin, A. M. (1983). Television uses and gratifications: The interactions of viewing patterns and motivations. Journal of Broadcasting, 27(1), 37-51.

Rubin, A. M. (1986). Television, aging and information seeking. Journal of Language \& Communication, 6(1/2), 125-137.

Rubin, A. M. (2009). Uses-and-gratifications perspective on media effects. In J. Bryant \& D. Zillmann (Eds.), Media effects: Advances in theory and research (pp. 165-184). New York, NY: Routledge.

Rubin, A. M., \& Perse, E. M. (1987a). Audience activities and television news gratifications. Communication Research, 14(1), 58-84.

Rubin, A. M., \& Perse, E. M. (1987b). Audience activities and soap opera involvement: A uses and effects investigation. Human Communication Research, 14(2), 246-268.

Rubin, A. M., \& Rubin, R. B. (1986). Contextual age as a life-position index. The International Journal of Aging and Human Development, 23(1), 27-45.

Rubin, A. M., \& Rubin, R. B. (1989). Social and psychological antecedents of VCR use. In M. R. Levy (Ed.), The VCR age: Home video and mass communication (pp. 92-111). Beverly Hills, CA: Sage.

Russell, C. A., Norman, A. T., \& Heckler S. E. (2004a). The consumption of television programming: Developing and validation of the connectedness scale. Journal of Consumer Research, 31(2), 150-161.

Russell, C. A., Norman, A. T., \& Heckler S. E. (2004b). People and their television shows: An overview of television connectedness. In L. J. Shrum (Ed.), The psychology of entertainment media: Blurring the lines between entertainment and persuasion (pp. 275-290). Mahwah, NJ: Lawrence Erlbaum Association, Inc.

Saade, R., \& Bahli, B. (2005). The impact of cognitive absorption on perceived usefulness and perceived ease of use in online learning: An extension of the technology acceptance model. Information \& Management, 42(1), 317-327.

Sultan, F. (2002). Consumer response to the Internet: An exploratory tracking study of on-line home users. Journal of Business Research, 55(8), 655-663.

Sun, T., Youn, S., Wu. G., \& Kuntaraporn, M. (2006). Online word-of-mouth (or mouse): An exploration of its antecedents and consequences. Journal of ComputerMediated Communication, 11(4), 1104-1127.

Tornatzky, L. G., \& Klein, K. J. (1982). Innovation characteristics and innovation adoption-implementation: A meta-analysis of findings. IEEE Transactions on Engineering Management, 29(1), 28-45. 
Winter, S., Krämer N. C., Benninghoff, B., \& Gallus, C. (2018). Shared entertainment, shared opinions: The influence of social TV comments on the evaluation of talent shows. Journal of Broadcasting \& Electronic Media, 62(1), 21-37.

Wohn, D. Y., \& Na, E. (2011). Tweeting about TV: Sharing television viewing experiences via social media message streams. First Monday, 16(3).

Youn, S. (1994). Program type preference and program choice in a multichannel situation. Journal of Broadcasting \& Electronic Media, 38(4), 465-476.

Zúñiga, H. G. D., Garcia-Perdomo, V., \& McGregor, S. C.
(2015). What is second screening? Exploring motivations of second screen use and its effect on online political participation, Journal of Communication, 65(5), 793-815.

Zywica, J., \& Danowski, J. (2008). The faces of facebookers: Investigating social enhancement and social compensation hypotheses; predicting Facebook and offline popularity from sociability and self-esteem, and mapping the meanings of popularity with semantic networks. Journal of Computer-Mediated Communication, 14(1), 1-34.

\section{About the Author}

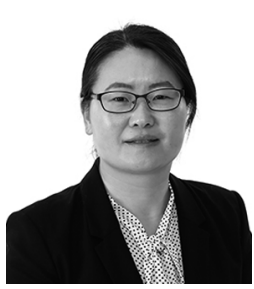

Miao Guo (PhD, University of Florida) is an Associate Professor in the Department of Telecommunications at Ball State University. Her research interests center on audience analytics, social media, and communication technology. 